\title{
Hypoxemia and prone position in mechanically ventilated COVID-19 patients: a prospective cohort study
}

\author{
Osama Abou-Arab, MD, PhD • Guillaume Haye, MD • Christophe Beyls, MD • \\ Pierre Huette, MD • Pierre-Alexandre Roger, MD • Mathieu Guilbart, MD • \\ Michaël Bernasinski, MD · Patricia Besserve, MD · Faouzi Trojette, MD · \\ Hervé Dupont, MD, PhD · Vincent Jounieaux, MD, PhD · Yazine Mahjoub, MD, \\ PhD
}

Received: 8 July 2020/Revised: 17 September 2020/Accepted: 22 October 2020/Published online: 4 November 2020

(c) Canadian Anesthesiologists' Society 2020

\section{To the Editor,}

During the coronavirus disease (COVID-19) outbreak, patients with severe COVID-19 related acute respiratory distress syndrome (ARDS) were admitted to our tertiary hospital intensive care unit (ICU). The benefits of prone position (PP) on survival have been highlighted in previous ARDS studies. ${ }^{1}$ The aim of this study was to report the effects of PP in mechanically ventilated patients with COVID-19 related ARDS.

Between 1 March 2020 and 30 April 2020, we prospectively included all patients admitted to our ICU with COVID-19 related acute respiratory failure. COVID19 was diagnosed by real-time reverse transcription polymerase chain reaction (rRT-PCR) test on a nasopharyngeal swab. During this period, 70 patients with confirmed COVID-19 were admitted; 64 (91\%) received invasive mechanical ventilation during the course of the disease. They were ventilated with low

Electronic supplementary material The online version of this article (https://doi.org/10.1007/s12630-020-01844-9) contains supplementary material, which is available to authorized users.

This article was updated to replace an incorrect version that was published due to an error in the production process.

O. Abou-Arab, MD, PhD · G. Haye, MD · C. Beyls, MD

P. Huette, MD - P.-A. Roger, MD - M. Guilbart, MD .

M. Bernasinski, MD - P. Besserve, MD - F. Trojette, MD .

H. Dupont, MD, PhD · Y. Mahjoub, MD, PhD ( $₫)$.

Department of Anesthesia and Critical Care Medicine, Amiens

University Medical Center, Amiens, France

e-mail: mahjoub.yazine@chu-amiens.fr

\section{Jounieaux, MD, PhD}

Respiratory Department, Amiens University Medical Center, Amiens, France tidal volume $\left(\leq 6 \mathrm{~mL} \cdot \mathrm{kg}^{-1}\right)$, plateau pressure below 30 $\mathrm{cmH}_{2} \mathrm{O}$, low driving pressure $\left(\leq 15 \mathrm{cmH}_{2} \mathrm{O}\right)$, and positive end-expiratory pressure according to the strategy proposed by the ARDS Network. ${ }^{2}$ Patients for whom the ratio of arterial oxygen partial pressure to fractional inspired oxygen $\left(\mathrm{PaO}_{2} / \mathrm{F}_{1} \mathrm{O}_{2}\right)$ ratio remained below 150 for $12 \mathrm{hr}$ despite this protective ventilation received at least one 16-hr PP session (flow chart, eFigure in Electronic Supplementary Material [ESM]). All patients were sedated and paralyzed before PP. Respiratory parameters were recorded before and at the end of the first 16-hr PP session. The compliance of the respiratory system (Crs) was calculated as tidal volume/(plateau pressure minus end-expiratory pressure). Ventilator settings were not modified during $\mathrm{PP}$, and $\mathrm{F}_{1} \mathrm{O}_{2}$ was adjusted for a target peripheral oxygen saturation $\left(\mathrm{SpO}_{2}\right)$ of $92 \%$.

Our local institutional review board waived the need for written consent and data collection was approved by the French licensing authority (number: PI2020_843_0026). Oral and written information was provided to the patients and their families. All parameters were compared using a Wilcoxon rank-sum test and $P<0.05$ was considered as significant.

Twenty-five patients were analyzed. Clinical data appear in the ESM eTable. Prone position procedures significantly increased $\mathrm{PaO}_{2} / \mathrm{F}_{1} \mathrm{O}_{2}$ ratio (95\% confidence interval [CI]) from 91 (78 to 137) to 124 (97 to 149) $\mathrm{mmHg}$ $(P=0.008)$. Arterial partial pressure of carbon dioxide $\left(\mathrm{PaCO}_{2}\right)$ remained unchanged [from 49 (42 to 51 ) to 49 (44 to 57$) \mathrm{mmHg} ; P=0.55$ ], as did Crs [from 32 (21 to 38 ) to 32 (23 to 40 ) $\mathrm{mL} \cdot \mathrm{cmH}_{2} \mathrm{O}^{-1} ; P=0.33$ (Figure)], plateau pressure [from 28 (25 to 30) to 25 (24 to 29 ) $\mathrm{cmH}_{2} \mathrm{O} ; P=$ 0.16 ] and ventilatory ratio [from 2.01 (1.47 to 2.51 ) to 1.98 (1.42 to 2.46$) ; P=0.98]$. 
Figure Effect of prone positioning on respiratory parameters. Changes in the ratio of arterial oxygen partial pressure to fractional inspired oxygen $\left(\mathrm{PaO}_{2} / \mathrm{F}_{1} \mathrm{O}_{2}\right)$,

respiratory system compliance (Crs) and arterial partial pressure of carbon dioxide $\left(\mathrm{PaCO}_{2}\right)$ from supine to prone position (PP)
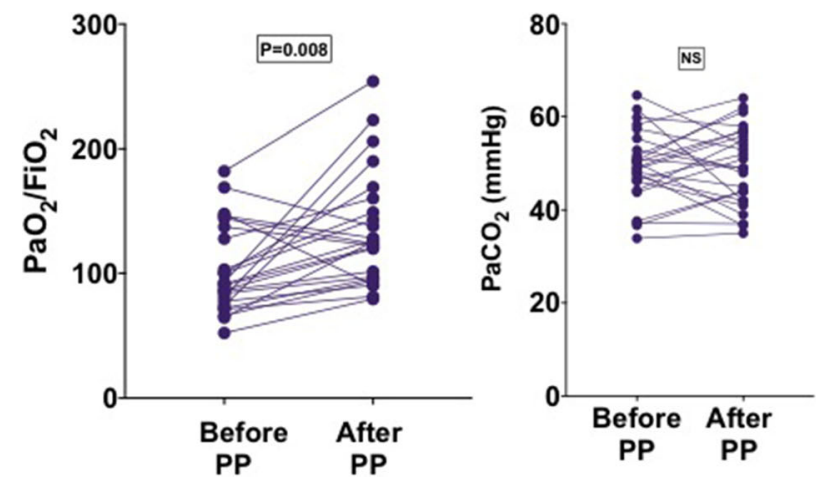

Prone position significantly improved oxygenation without any change in $\mathrm{PaCO}_{2}$ or $\mathrm{Crs}$ in our population of mainly male patients. One of the beneficial effects of PP is the recruitment of non-aerated areas of the lungs. Previous studies have shown that improvement of $\mathrm{PaCO}_{2}$ with $\mathrm{PP}$ suggests lung recruitment. ${ }^{3}$ We found that $\mathrm{PaCO}_{2}$, plateau pressure, Crs, and ventilatory ratio (a surrogate for dead space; see eAppendix, ESM) remained stable suggesting a lack of significant lung recruitment induced by PP. Hence, the increase in $\mathrm{PaO}_{2} / \mathrm{F}_{1} \mathrm{O}_{2}$ ratio may be explained by an improvement in ventilation-to-perfusion ratio (VA/Q). Because ventilation is unchanged, VA/Q increase could only be explained by a decrease in pulmonary capillary flow (Q). If the decrease of $Q$ is sufficient to improve oxygenation, we may suggest that a major mechanism involved in COVID-19 related ARDS is a VA/Q mismatch and probably an intra-pulmonary shunt. ${ }^{4}$ Gattinoni et al. have observed an increased shunt fraction in COVID-19 "atypical ARDS" and suggested "hyperperfusion" of gasless tissue. ${ }^{5}$ In this hypothesis, because lung shape is conical, the distribution of the shunt that predominates in the larger (posterior) part may be reduced by PP explaining the significant improvement in $\mathrm{PaO}_{2} / \mathrm{F}_{1} \mathrm{O}_{2}$ ratio.

Despite its limited sample size, this study suggests that PP may improve oxygenation without changing ventilatory parameters, highlighting the possible role of a hidden intrapulmonary shunt. Further investigations are mandatory before any formal conclusion.

Acknowledgement The authors thank Prof. Antoine Gabrion and the "surgical DV team" for their help during the crisis.
Disclosures None.

Funding statement Only institutional funds were used for this study.

Editorial responsibility This submission was handled by Dr. Sangeeta Mehta, Associate Editor, Canadian Journal of Anesthesia.

\section{References}

1. Munshi L, Del Sorbo L, Adhikari NK, et al. Prone position for acute respiratory distress syndrome. A systematic review and meta-analysis. Ann Am Thorac Soc 2017; 14(Supplement_4): S280-8.

2. Writing Group for the Alveolar Recruitment for Acute Respiratory Distress Syndrome Trial (ART) Investigators; Cavalcanti $A B$, Suzumura EA, Laranjeira LN, et al. Effect of lung recruitment and titrated positive end-expiratory pressure (PEEP) $v s$ low PEEP on mortality in patients with acute respiratory distress syndrome: a randomized clinical trial. JAMA 2017; 318: 1335-45.

3. Protti A, Chiumello D, Cressoni $M$, et al. Relationship between gas exchange response to prone position and lung recruitability during acute respiratory failure. Intensive Care Med 2009; 35: 1011-7.

4. Mahjoub Y, Rodenstein DO, Jounieaux V. Severe Covid-19 disease: rather AVDS than ARDS? Crit Care 2020; https://doi. org/10.1186/s13054-020-02972-w.

5. Gattinoni L, Coppola S, Cressoni M, Busana M, Rossi S, Chiumello D. COVID-19 does not lead to a "typical" acute respiratory distress syndrome. Am J Respir Crit Care Med 2020; 201: $1299-300$.

Publisher's Note Springer Nature remains neutral with regard to jurisdictional claims in published maps and institutional affiliations. 